\title{
Effect of graphite particle fillers on dielectric and conductivity properties of poly(NIPAM-co-HEMA)
}

\author{
G TORĞUT ${ }^{1, *}$, F BIRYAN ${ }^{2}$ and K DEMIRELLI ${ }^{2}$ \\ ${ }^{1}$ Department of Chemistry and Chemical Processes, Tunceli Vocation School, Tunceli 62100, Turkey \\ ${ }^{2}$ Faculty of Science, Department of Chemistry, Firat University, Elazig 23169, Turkey \\ *Author for correspondence (gtorgut@munzur.edu.tr)
}

MS received 12 September 2018; accepted 17 April 2019

\begin{abstract}
Copolymers of 2-hydroxyethyl methacrylate (HEMA) and $N$-isopropylacrylamide (NIPAM) in different ratios were prepared by free radical polymerization using $2,2^{\prime}$-azobisisobutyronitrile as an initiator at $60^{\circ} \mathrm{C}$. The copolymers were analysed by Fourier transform infrared and proton nuclear magnetic resonance. Thermal behaviours were determined by thermogravimetric analysis and differential scanning calorimetry (DSC). DSC measurements showed that the glass transition temperature $\left(T_{\mathrm{g}}\right)$ of poly(HEMA) and poly(NIPAM) was 100 and $140^{\circ} \mathrm{C}$, respectively. Electrical properties (dielectric constant, dielectric loss and alternating current conductivity) of polymers and composites prepared with graphite were investigated by using an impedance analyser, in the range of $10-20 \mathrm{kHz}$. While the dielectric constant values vary from 3.3 to 4.01 for copolymers at $1 \mathrm{kHz}$, these values are increased about 10 times for composites doped with 10 wt $\%$ graphite. Similarly, the dielectric loss and conductivity values were fairly high for composites. The conductivity values of composites doped with $10 \mathrm{wt} \%$ graphite showed a significant increase and the insoluble polymer became semiconducting. It was observed that the electrical properties of graphite-added composites at different ratios $(8,9$ and 10 wt $\%)$ increased with the increase in graphite ratio for all polymers. In addition, the direct current conductivity of composites doped with $10 \mathrm{wt} \%$ graphite was examined according to the temperature and the activation energy $\left(E_{\mathrm{a}}\right)$ values were calculated.
\end{abstract}

Keywords. Composites; conductivity; dielectric constant; graphite; polymer characterization; radical polymerization.

\section{Introduction}

In recent years, the rapid development of electronic devices has led scientists to prepare electrically conductive communities. For this purpose, various fillers have been applied to conventional polymeric materials, which generally exhibit low modulus and poor electrical conductivity $[1,2]$. In this regard, polymer composites have been prepared using nanometricsized fillings, such as carbon black, carbon nanotubes, graphene and graphite sheets [3-6]. Thus, it has improved both the mechanical and physical properties of the polymers. When their unique electrical and mechanical properties combined with their elasticity, lightness, processability, thermal stability, etc., they have found wide application areas like aerospace and marine systems, thermistors, energy storage devices, capacitors, light emitting diodes, gas sensors, batteries, etc. [7,8]. Polymer nanocomposites filled with conducting components have become remarkable around the world with their usage in many fields.

Graphite is a pure and two-dimensional crystalline form of carbon in which atoms are strongly bonded to each other. Because the layers are bound by weak van der Waals forces, the material can be easily dispersed in the polymer [9]. When compared with other fillers, it shows the best performance in terms of electrical and thermal conductivities. Also, it has been widely used as an electronically conducting filler in the preparation of conducting polymer composites due to its natural abundance and low cost. It is highly advantageous to use it in a commercial perspective as well $[10,11]$. Graphite is more preferred than other fillers because of its ability to increase the tensile strength and impart chemical resistance of the composite as well as its conductivity $[12,13]$.

The electrical properties of polymer composites using graphite as a filler material have been extensively studied in the last decade. To achieve a good conductivity of a composite, about $20 \%$ of filler is required. Electrically conductive composites were prepared by using polymers, such as polystyrene, polyethylene, poly(methyl methacrylate) and polypropylene with nanographite layers [14-17]. Functional groups, such as $\mathrm{C}-\mathrm{O}-\mathrm{C}, \mathrm{C}-\mathrm{OH}$ and $\mathrm{C}-\mathrm{O}$ in the graphite structure increase the interaction between the graphite and the polymer and allow the graphite nanoplates to be well dispersed in the polymer. It is well known that the homogeneous distribution of the conductor filler in the polymer is very important for preparing high-performance composites [18,19]. It is expected that the 
<smiles>CC(C)NC(=O)C(C(C)(C)C)C(C)(C)CC(C)(C)C(C)(C(=O)OCCO)C(C)(C)C</smiles>

HEMA units

Scheme 1. Structure of the copolymer system prepared with HEMA and NIPAM.

lower the volume fraction, the more increase in the dielectric constant in these prepared nanocomposites [20]. In conductive polymer composites, the dielectric constant increases with an increase in the conducting filler and especially near the percolation threshold, a significant increase is observed [21]. The dielectric properties of the composites vary depending on the size and shape of the conductive filler, the volume fraction, the method of preparation and the interaction between the filler material and the polymer. These composites which have a high-dielectric constant can be used as embedded capacitors. For this reason, it has become a focus of attention nowadays to study the dielectric properties of polymer composites as a function of the filler material and frequency.

In the present study, $N$-isopropylacrylamide-co-2-hydroxyethyl methacrylate (NIPAM-co-HEMA) copolymers were synthesized at four different HEMA ratios and the characterization of the polymers was reported by proton nuclear magnetic resonance $\left({ }^{1} \mathrm{H}-\mathrm{NMR}\right.$ and $\left.{ }^{13} \mathrm{C}-\mathrm{NMR}\right)$, Fourier transform infrared (FTIR) and thermal analysis techniques (differential scanning calorimetry (DSC) and thermogravimetric analysis (TGA)). Composites (copolymergraphite) were prepared by dispersing the copolymers with commercial graphite in a copolymer solution via a solution method. The dielectric constant $\left(\varepsilon^{\prime}\right)$, dielectric loss $\left(\varepsilon^{\prime \prime}\right)$ and electrical conductivity $\left(\sigma_{\mathrm{ac}}\right)$ of pure copolymers and copolymer composite-based graphite in different compositions (8, 9 and $10 \mathrm{wt} \%)$ were analysed as a dependence on the frequency at room temperature by using an impedance analyser over the frequency range of $10 \mathrm{~Hz}-$ $20 \mathrm{kHz}$ and compared with each other. To investigate the effect of copolymer compositions on the electrical behaviour, $\varepsilon^{\prime}, \varepsilon^{\prime \prime}$ and $\sigma_{\mathrm{ac}}$ parameters for $10 \mathrm{wt} \%$ graphite-based composites have been studied as a function of frequency. Also, activation energy $\left(E_{\mathrm{a}}\right)$ of composites doped with $10 \mathrm{wt} \%$ graphite and $\sigma_{\mathrm{dc}}$ were calculated from graphs of $\ln \sigma_{\mathrm{dc}}-1000 / T$.

\section{Experimental}

\subsection{Materials and methods}

NIPAM, HEMA and graphite were purchased commercially from Sigma-Aldrich and used in their pure state. 2,2'azobisisobutyronitrile (AIBN) is used as an initiator.

\subsection{Synthesis of copolymers}

The free radical polymerization method was used to prepare the copolymers. The copolymerization of HEMA and NIPAM

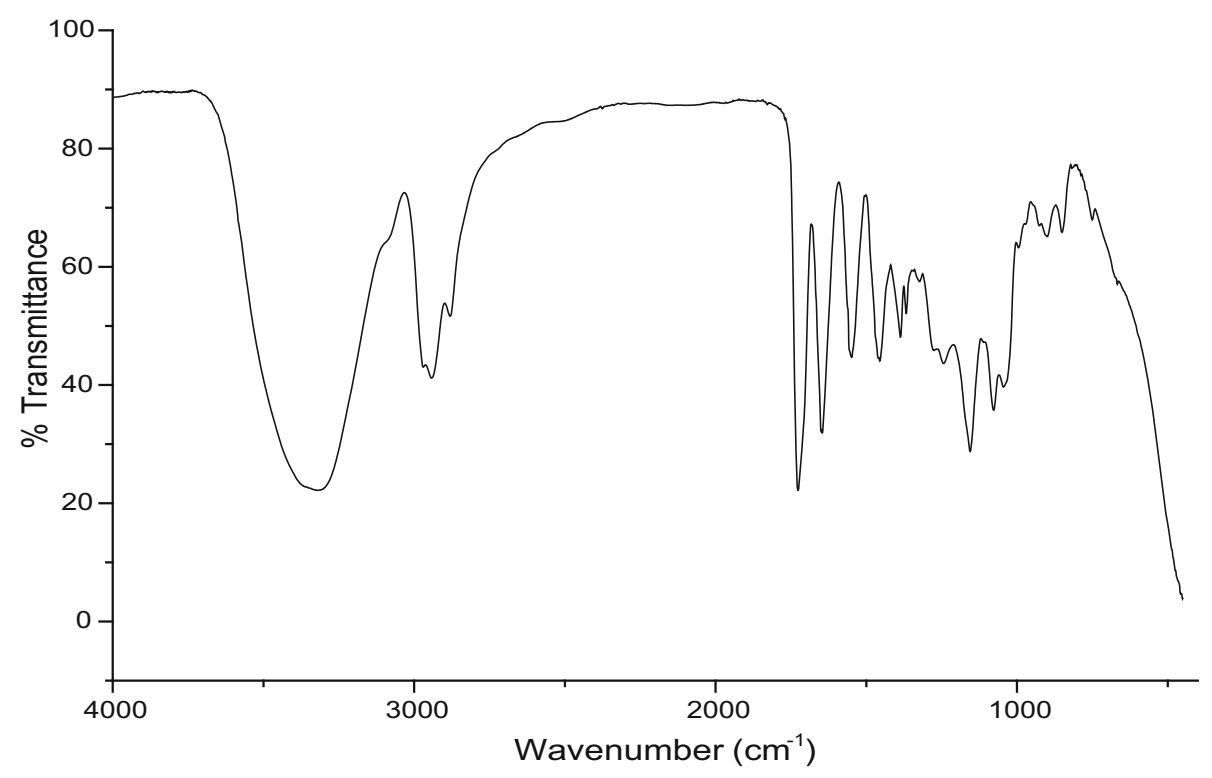

Figure 1. IR spectrum of poly(HEMA-co-NIPAM) copolymers. 

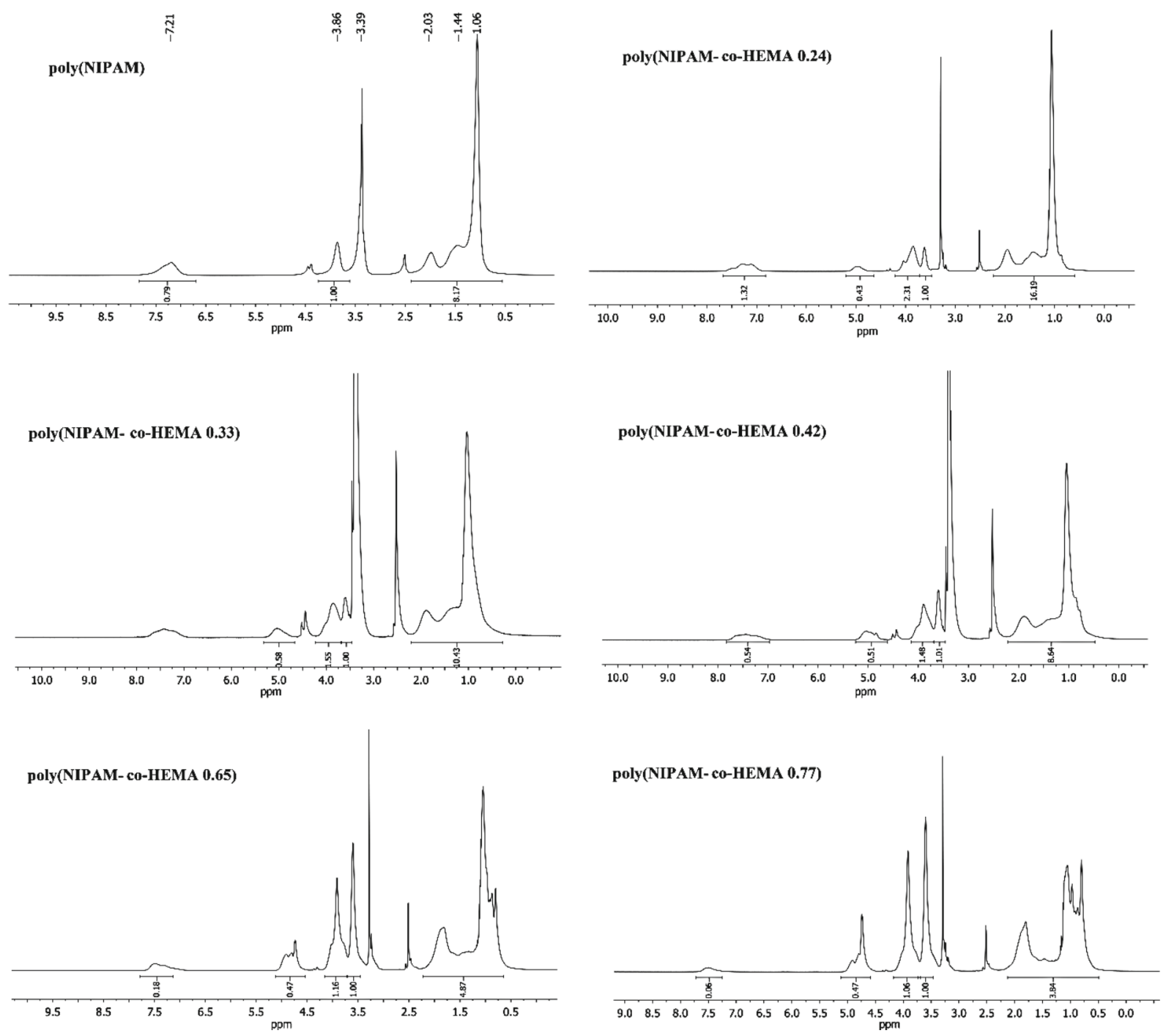

Figure 2. ${ }^{1} \mathrm{H}-\mathrm{NMR}$ spectra of the copolymer series.

was carried out in a methanol solvent using AIBN as an initiator at $60^{\circ} \mathrm{C}$. After $5 \mathrm{~h}$, the polymers were cooled to room temperature and precipitated in diethyl ether and was dried in a vacuum at $40^{\circ} \mathrm{C}$ for $24 \mathrm{~h}$.

\subsection{Preparation of graphite-based poly(HEMA-NIPAM) composites}

Copolymers were dissolved completely in $10 \mathrm{ml}$ methanol and to ensure homogeneous distribution, it is stirred with graphite weighed in a certain ratio at room temperature in an ultrasonic bath for $1 \mathrm{~h}$. Then, the solution was precipitated in diethyl ether and was dried in a vacuum at $40^{\circ} \mathrm{C}$ for $24 \mathrm{~h}$.

\subsection{Characterization}

FTIR transmission spectra were recorded using a Mattson 1000 spectrometer in the wavenumber range of 400 $4000 \mathrm{~cm}^{-1}$. ${ }^{1} \mathrm{H}$-NMR and ${ }^{13} \mathrm{C}-\mathrm{NMR}$ spectra were recorded on an AVANCE III $400 \mathrm{MHz}$ Bruker. DSC thermograms of all the polymers were recorded in the temperature range from 25 to $200^{\circ} \mathrm{C}$ at a heating rate of $20^{\circ} \mathrm{C} \mathrm{min}^{-1}$ and glass transition temperatures $\left(T_{\mathrm{g}}\right)$ were determined. TGA was performed using a Shimadzu TGA-50 to determine the thermal stability of the polymers. For this purpose, polymer samples weighed in specific amounts were heated from 25 to $500^{\circ} \mathrm{C}$ with a heating rate of $10^{\circ} \mathrm{C} \mathrm{min}{ }^{-1}$ in a nitrogen gas atmosphere.

\subsection{Dielectric and electrical properties of polymers}

A QuadTech 7600 LRC impedance analyser was used for dielectric spectroscopy measurements. Measurements of the copolymer samples prepared by applying 4 ton pressure were taken between a frequency of $100 \mathrm{~Hz}$ and $20 \mathrm{kHz}$ at room temperature. The polymers were compressed between parallel gold plates and the capacitance values were measured. The dielectric constant (1) and dielectric loss (2) 

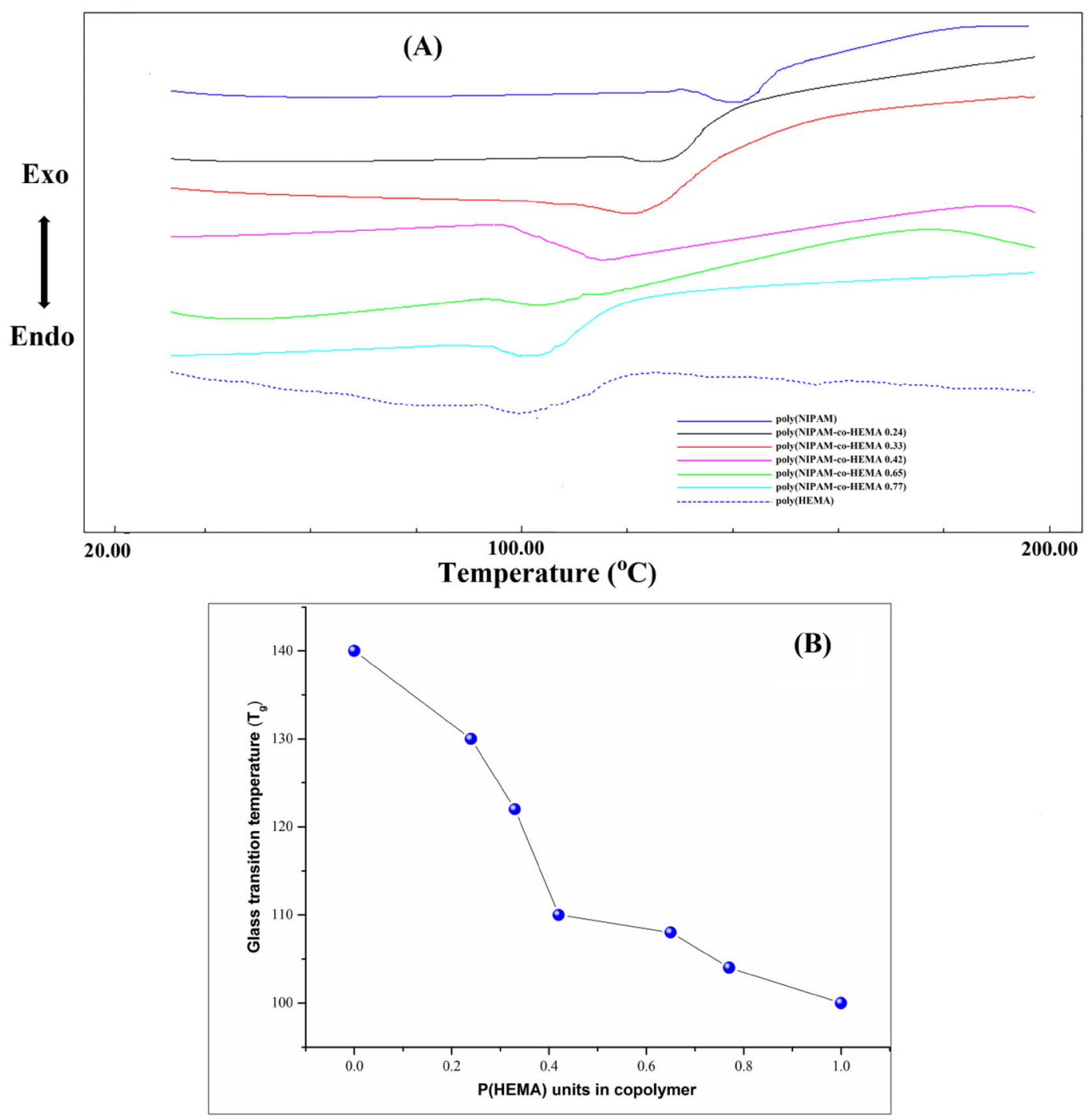

Figure 3. (A) DSC curves of the HEMA-NIPAM copolymer system, poly(HEMA) and poly(NIPAM) and (B) change of $T_{\mathrm{g}}$ as a function of the mol\% HEMA unit in the copolymer.

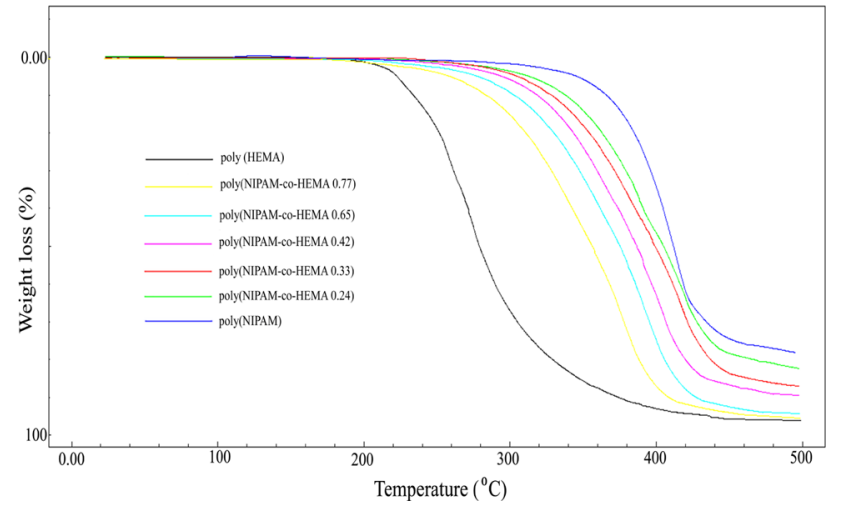

Figure 4. TGA curves of the HEMA-NIPAM copolymer system, $\mathrm{P}(\mathrm{HEMA})$ and $\mathrm{P}(\mathrm{NIPAM})$.
Table 1. TGA and DSC results of copolymer series.

\begin{tabular}{lcccc}
\hline & $\begin{array}{c}T_{\mathrm{g}} \\
\left({ }^{\circ} \mathrm{C}\right)\end{array}$ & $\begin{array}{c}T_{\text {initial }} \\
\left({ }^{\circ} \mathrm{C}\right)\end{array}$ & $\begin{array}{c}T_{\text {final }} \\
\left({ }^{\circ} \mathrm{C}\right)\end{array}$ & Residue\% \\
\hline Poly(HEMA) & 100 & 220 & 394 & 5 \\
Poly(NIPAM-co-HEMA 0.77) & 104 & 361 & 412 & 6 \\
Poly(NIPAM-co-HEMA 0.65) & 108 & 352 & 424 & 7 \\
Poly(NIPAM-co-HEMA 0.42) & 110 & 340 & 431 & 11 \\
Poly(NIPAM-co-HEMA 0.33) & 122 & 131 & 442 & 13 \\
Poly(NIPAM-co-HEMA 0.24) & 130 & 290 & 443 & 18 \\
Poly(NIPAM) & 140 & 380 & 451 & 20 \\
\hline
\end{tabular}

were calculated using the following formulae:

$$
\varepsilon^{\prime}=\frac{C d}{\varepsilon_{0 \mathrm{~A}}},
$$



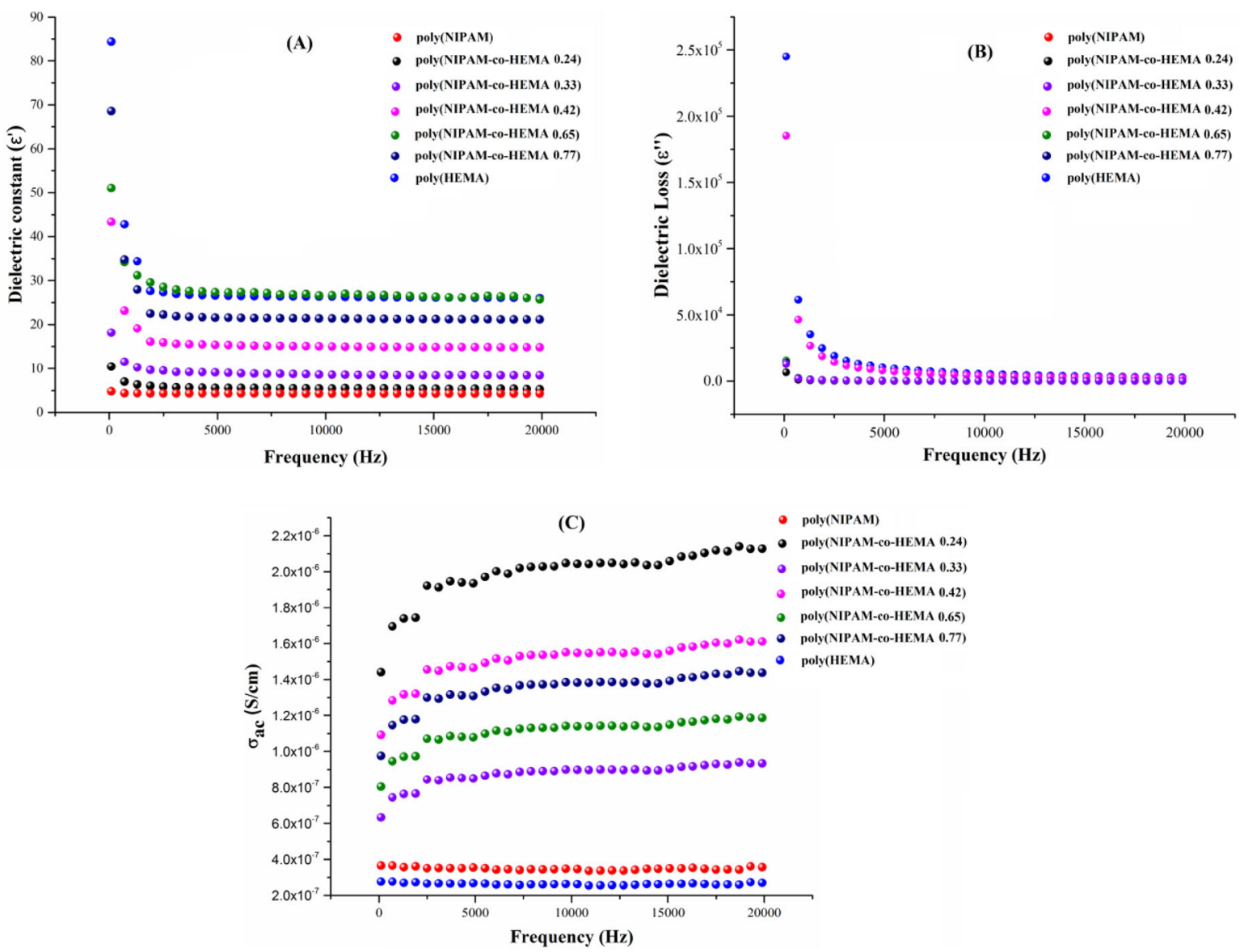

Figure 5. Frequency dependence of the $(\mathbf{A}) \varepsilon^{\prime},(\mathbf{B}) \varepsilon^{\prime \prime}$ and $(\mathbf{C})$ ac conductivity for the composite series doped with $10 \mathrm{wt} \%$ graphite.

Table 2. Dielectric and electrical properties of the pure copolymer series at $1 \mathrm{kHz}$ at $25^{\circ} \mathrm{C}$.

\begin{tabular}{lllll}
\hline Sample & $\varepsilon^{\prime}$ & $\varepsilon^{\prime \prime}$ & $\sigma\left(\mathrm{S} \mathrm{cm}^{-1}\right)$ & $1.06 \times 10^{-9}$ \\
\hline P(NIPAM) & 3.33 & 0.031 & $1.17 \times 10^{-9}$ & -8.97 \\
Poly(NIPAM-co-HEMA 0.24) & 3.37 & 0.036 & $1.31 \times 10^{-9}$ & -8.92 \\
Poly(NIPAM-co-HEMA 0.33) & 3.41 & 0.041 & $1.49 \times 10^{-9}$ & -8.87 \\
Poly(NIPAM-co-HEMA 0.42) & 3.54 & 0.052 & $1.68 \times 10^{-9}$ & -8.83 \\
Poly(NIPAM-co-HEMA 0.65) & 3.57 & 0.059 & $1.92 \times 10^{-9}$ & -8.87 \\
Poly(NIPAM-co-HEMA 0.77) & 3.86 & 0.061 & $1.98 \times 10^{-9}$ & -8.72 \\
Poly(HEMA) & 4.01 & 0.064 & & -8.70 \\
\hline
\end{tabular}

$$
\varepsilon^{\prime \prime}=\varepsilon^{\prime} D_{\mathrm{F}}
$$

where $\varepsilon_{0}=8.85 \times 10^{-12} \mathrm{~F} \mathrm{~m}^{-1}$ is the permittivity of vacuum, $A$ is the area of the gold plates and $d$ is the thickness of the sample.

\section{Results and discussion}

\subsection{Characterization of polymers}

The chemical structure of the copolymer is shown in scheme 1. The FTIR spectra of poly(HEMA-co-NIPAM) obtained via free-radical polymerization are shown in figure 1 . The strong band at $3363 \mathrm{~cm}^{-1}$ is assigned to the $\mathrm{OH}$ band at HEMA, $1724 \mathrm{~cm}^{-1}$ to the stretching vibration of the carbonyl group $(\mathrm{O}-\mathrm{C}=\mathrm{O})$ in the ester of HEMA and the two obvious peaks at $1648 \mathrm{~cm}^{-1}$ are associated with the carbonyl group of amide groups in NIPAM. The ${ }^{1} \mathrm{H}-\mathrm{NMR}$ spectra of poly(HEMAco-NIPAM) copolymer series are shown in figure 2 . The aliphatic protons on the main backbone and $-\mathrm{CH}_{3}$ protons in NIPAM units were observed in the range of 1-2.03. The methylene protons $\left(-\mathrm{CH}_{2} \mathrm{OCO}\right)$ next to the ester oxygen in HEMA units were observed at $3.68 \mathrm{ppm}$ and the $(\mathrm{CHOCNH})$ protons next to the amide in NIPAM units were observed at 
3.86 ppm. $-\mathrm{CH}_{3}$ protons in NIPAM units were observed at $7.21 \mathrm{ppm}$.

\subsection{Thermal behaviour of polymers}

The thermal behaviour of copolymers was examined by DSC in the temperature range of $0-200^{\circ} \mathrm{C}$. As shown in figure $3 \mathrm{~A}$, the glass transition temperature $\left(T_{\mathrm{g}}\right)$ of NIPAM and HEMA homopolymers is 140 and $100^{\circ} \mathrm{C}$, respectively. In figure 3B, the change of $T_{\mathrm{g}}$ is illustrated as a function of mol\% HEMA unit in the copolymer. The $T_{\mathrm{g}}$ values of all the copolymers were between these values and showed a single transition. TGA measurements were taken under nitrogen gas to determine the thermal stability of the copolymers. The TGA curves of the polymers are compared in figure 4. It has been observed that the decomposition of all copolymers occurred in single stage and that the degradation temperatures are between the HEMA and NIPAM homopolymers. The decomposition temperatures varied from 218 to $360^{\circ} \mathrm{C}$. The results are summarized in table 1.

\subsection{Dielectric and electrical properties of polymers}

While the orientation polarization is related to the molecular polarity, the induced polarization is due to the transfer of electrons under the external electric field. The improvement of the polymer polarity does not only increase the orientation polarization, but also makes it easier to stimulate the electrons. The group with more polar atoms and symmetric structure has a stronger molecular polarity. The ester group shows a stronger relative polarity than the other groups. Under an external electric field, the stronger molecular polarity increases both the orientation polarization and the excited polarization, as well as brings greater polarizability and higher permittivity [22].

The frequency dependence of the $\varepsilon^{\prime}$ for pure polymers is shown in figure $5 \mathrm{~A}$. It was found that the $\varepsilon^{\prime}$ decreased with an increase in the frequency at room temperature. Especially, at low-frequencies $\varepsilon^{\prime}$ values were higher due to electronic, atomic, ionic and interface or space charge polarizations [23]. Electrons and atoms are displaced when the polymers are left in an alternative electric field, so the centres of the electrical charge shift, resulting in electrical polarization. The dipoles need time to reach the equilibrium state called the relaxation time. One of the reasons for the decrease in $\varepsilon^{\prime}$ at high-frequencies is that it does not have enough time for relaxation. Only electrical polarization occurs at high-frequencies, so the number of dipoles is few and the $\varepsilon^{\prime}$ is small. In figure $5 \mathrm{~A}$, it is clear that the $\varepsilon^{\prime}$ increased from 3.37 to 3.86 with an increase in the HEMA ratio for all frequencies due to the presence of polar groups such as $\mathrm{OH}$ and $\mathrm{C}=\mathrm{O}$ groups in
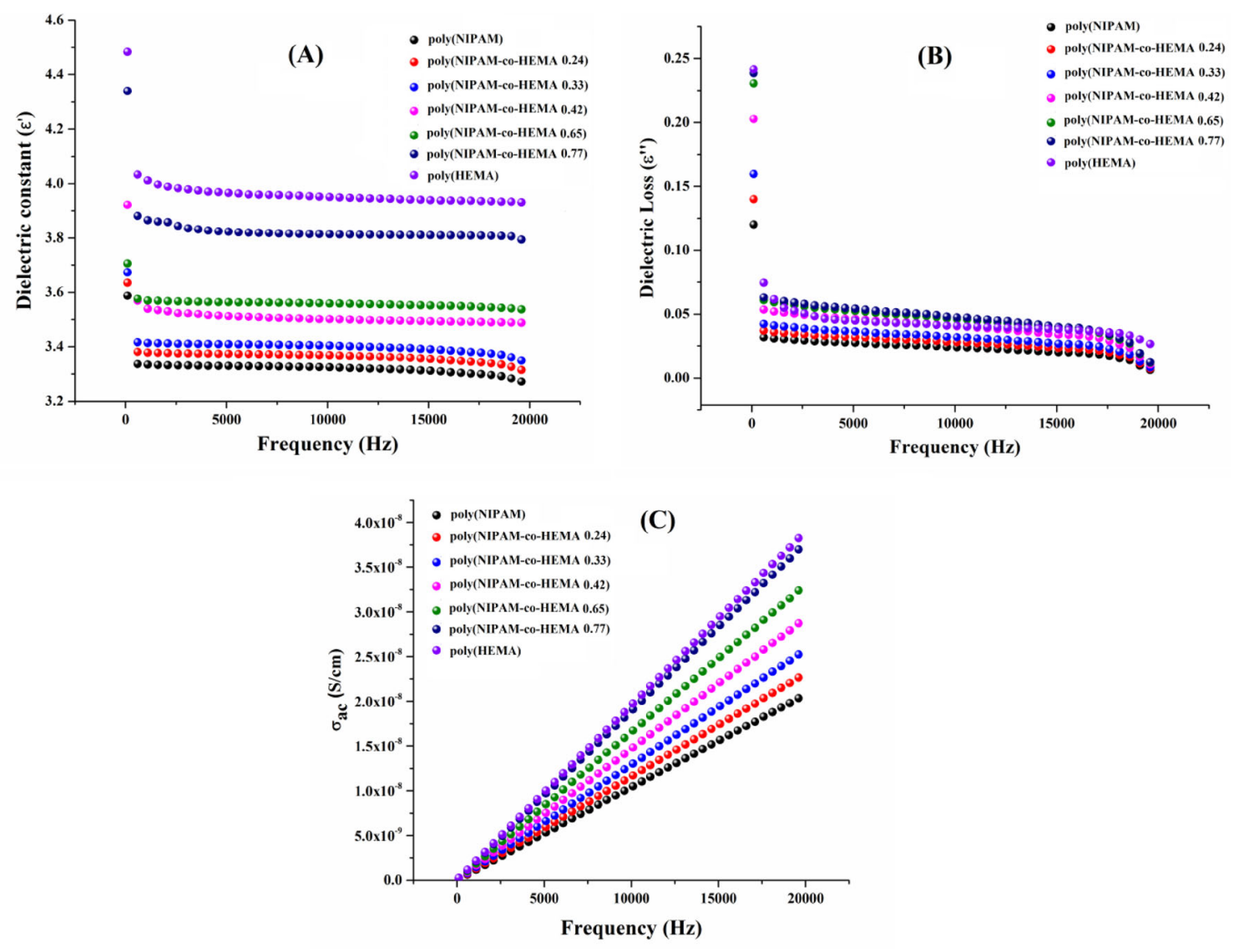

Figure 6. Frequency dependence of the $(\mathbf{A}) \varepsilon^{\prime},(\mathbf{B}) \varepsilon^{\prime \prime}$ and $(\mathbf{C})$ ac conductivity for the pure copolymer series. 
Table 3. Dielectric and electrical properties of the composite series doped with $10 \mathrm{wt} \%$ graphite at $1 \mathrm{kHz}$ at $25^{\circ} \mathrm{C}$.

\begin{tabular}{lrrrr}
\hline Sample & $\varepsilon^{\prime}$ & $\varepsilon^{\prime \prime}$ & $\sigma\left(\mathrm{S} \mathrm{cm}^{-1}\right)$ & $\ln ^{\prime}\left(\mathrm{S} \mathrm{cm}^{-1}\right)$ \\
\hline P(NIPAM) & 4.40 & 26 & $3.56 \times 10^{-7}$ & -14.84 \\
Poly(NIPAM-co-HEMA 0.24) & 6.56 & 493 & $2.74 \times 10^{-7}$ & -15.11 \\
Poly(NIPAM-co-HEMA 0.33) & 10.63 & 725 & $7.65 \times 10^{-7}$ & -14.08 \\
Poly(NIPAM-co-HEMA 0.42) & 16.24 & 1034 & $1.16 \times 10^{-6}$ & -13.66 \\
Poly(NIPAM-co-HEMA 0.65) & 28.82 & 1278 & $1.18 \times 10^{-6}$ & -13.65 \\
Poly(NIPAM-co-HEMA 0.77) & 32.01 & 26,622 & $1.31 \times 10^{-6}$ & -13.54 \\
P(HEMA) & 35.45 & 35,323 & $1.73 \times 10^{-6}$ & -13.26 \\
\hline
\end{tabular}
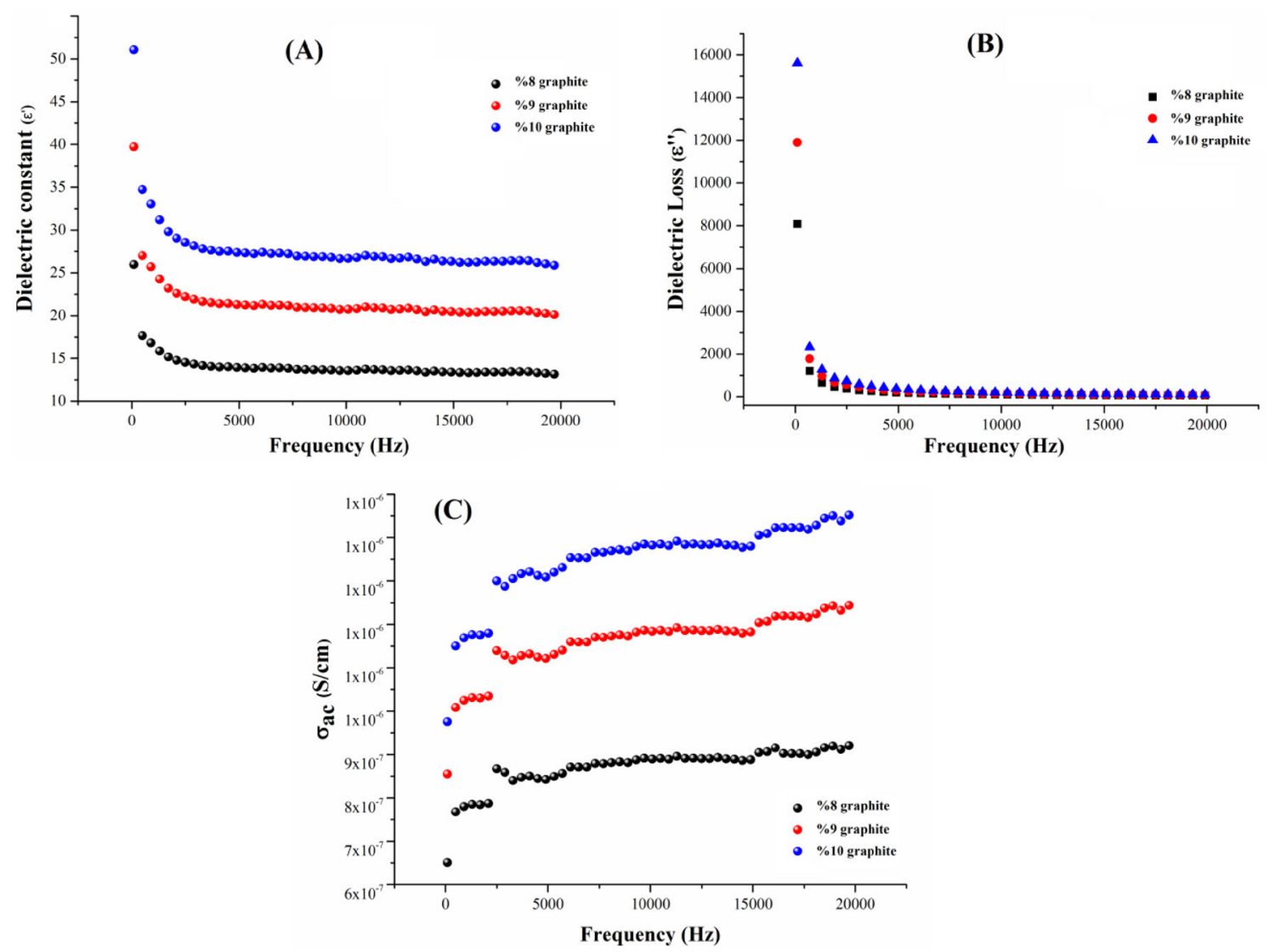

Figure 7. Frequency dependence of the $(\mathbf{A}) \varepsilon^{\prime},(\mathbf{B}) \varepsilon^{\prime \prime}$ and $(\mathbf{C})$ ac conductivity for the composite series doped with 8 , 9 and $10 \mathrm{wt} \%$ graphite.

HEMA. OH groups in the HEMA unit of the copolymer have orientation polarization and are easily aligned in the electric field [24]. The decrease of $\varepsilon^{\prime}$ with an increase in the frequency may be attributed to the electrical relaxation processes. The material electrode interface polarization superimposed with other relaxation processes at low-frequencies [25]. The larger values of the dielectric constant at lower frequencies are due to all contributions like electronic, ionic, electrode and grain boundary effects, whereas at high-frequencies it is only due to the only electronic and ionic polarizations $[26,27]$. Up to the relaxation frequency, the full polarization occurs resulting in a high $\varepsilon^{\prime}$ value. Beyond the relaxation frequency, the missing polarization takes place and $\varepsilon^{\prime}$ is decreased (table 2).

High $\varepsilon^{\prime}$ and low $\varepsilon^{\prime \prime}$ have received considerable attention due to their technological applications such as in capacitors [7]. The low $\varepsilon^{\prime \prime}$ will be the potential for the industrial application. Figure 5B displays the frequency dependence of $\varepsilon^{\prime \prime}$. It is clear to observe that the $\varepsilon^{\prime \prime}$ decreases with increasing frequency such as $\varepsilon^{\prime}$ due to the relaxation arising from the interfacial polarization from $50 \mathrm{~Hz}$ to $20 \mathrm{kHz}$. The higher value of $\varepsilon^{\prime \prime}$ at a low-frequency is due to the free charge motion within the materials [28]. In addition, at room temperature, the higher 
value of $\varepsilon^{\prime \prime}$ at a low-frequency is due to the free charge motion within the materials and also the appearance of reduction is attributed to the relaxation phenomena of the polymer [25]. While $\varepsilon^{\prime}$ is 4.35 for poly(NIPAM-co-HEMA 0.77 ) at $50 \mathrm{~Hz}$, it is 3.8 at $20 \mathrm{kHz}$ at room temperature. Similarly, while $\varepsilon^{\prime \prime}$ is 0.23 for poly(NIPAM-co-HEMA 0.77 ) at $50 \mathrm{~Hz}$, it is 0.001 at $20 \mathrm{kHz}$ at room temperature.

The alternate current $(\mathrm{ac})$ electrical conductivity $\left(\sigma_{\mathrm{ac}}\right)$ of polymers in the frequency range from $50 \mathrm{~Hz}$ to $20 \mathrm{kHz}$ was calculated using the measured conductance $(G)$ by the following formula:

$$
\sigma=G \frac{d}{A}
$$

where $d$ is the thickness of the sample and $A$ is the area of the gold plates.

Figure 5C shows the frequency dependence of the $\sigma_{\mathrm{ac}}$ of the pure copolymers at room temperature. The $\sigma_{\mathrm{ac}}$ increases linearly with an increase in the frequency for all polymers. Increasing the $\sigma_{\mathrm{ac}}$ by increasing the frequency is a common property not only for semiconductor materials, but also for polymeric materials and is caused by ion mobility. It can be clearly seen from figure $5 \mathrm{C}$ that an increase in the HEMA content leads to an increase in conductivity. While $\sigma$ is $1.92 \times$ $10^{-9}$ for poly(NIPAM-co-HEMA 0.77 ), it is $1.17 \times 10^{-9}$ for poly(NIPAM-co-HEMA 0.24).

Figure 6A shows the $\varepsilon^{\prime}$ dependence of frequency for composites containing $10 \mathrm{wt} \%$ graphite at room temperature. The $\varepsilon^{\prime}$ increased from 4.5 for pure poly(HEMA) to 85 for the composite containing $10 \%$ graphite at $50 \mathrm{~Hz}$. This has shown that the graphite addition increases polarization under the electric field. When the graphite is added to the polymer, aggregates of graphite particles are formed and the average polarity of the aggregates is higher than the polarization of the individual particles $[29,30] . \varepsilon^{\prime}$ decreases with an increase in the frequency containing $10 \mathrm{wt} \%$ graphite of the composites. But it can be seen that the $\varepsilon^{\prime}$ of nanocomposites is not affected much as the frequency increases. A similar trend in $\varepsilon^{\prime}$ was observed for all composites and an increase in $\varepsilon^{\prime}$ with increasing HEMA. In figure $6 \mathrm{~B}$, when the variation of $\varepsilon^{\prime \prime}$ with frequency is examined at room temperature, it has been observed that there is an extreme increase for all composites containing $10 \mathrm{wt} \%$ graphite. Composites having high $\varepsilon^{\prime \prime}$ values due to the formation of conductive paths and the interfacial polarization are very useful in applications such as electromagnetic wave absorption and high-charge storage capacitors [31,32]. In addition, the $\varepsilon^{\prime \prime}$ decreases with an increase in the frequency. The reason for a high value of $\varepsilon^{\prime \prime}$ in the low-frequency region is the enhancement of mobility of charge carriers by adding graphite to the composites [25].

Figure 6C shows the frequency dependence of the $\sigma_{\mathrm{ac}}$ for composites at room temperature. ac conductivity increased almost linearly with frequency due to the interfacial polarization and the dielectric relaxation processes occurring in the composites [33]. In addition, the increased amount of HEMA in the composites significantly increased the $\sigma_{\mathrm{ac}}$. The $\sigma_{\mathrm{ac}}$ value increased from $2.74 \times 10^{-7}$ for poly(NIPAMco-HEMA 0.24 ) to $1.31 \times 10^{-6}$ for poly(NIPAM-co-HEMA $0.77)$ at $1 \mathrm{kHz}$ and $25^{\circ} \mathrm{C}$. All these results are summarized in table 3 .

The variation of $\varepsilon^{\prime}$ and $\varepsilon^{\prime \prime}$ with loading different ratios (8, 9 and $10 \mathrm{wt} \%$ ) of graphite in poly(NIPAM-co-HEMA 0.42) is shown in figure $7 \mathrm{~A}$ and $\mathrm{B}$, respectively. Both $\varepsilon^{\prime}$ and $\varepsilon^{\prime \prime}$ increased with an increase in the graphite ratio in a composite series. The value of $\varepsilon^{\prime}$ for the composite containing $8 \mathrm{wt} \%$ graphite increased from 17.39 to 34.18 for $10 \mathrm{wt} \%$ graphite at $1 \mathrm{kHz}$. The reason for the increase in $\varepsilon^{\prime}$ is the increase in the electric field in which the load carriers can easily pass with the graphite ratio [34]. $\varepsilon^{\prime \prime}$ may be due to the increase in the mobility of the load carriers with graphite loading. There appears to be little effect on $\varepsilon^{\prime}$ and $\varepsilon^{\prime \prime}$ of the high-frequencies in the shapes. $\varepsilon^{\prime}$ and $\varepsilon^{\prime \prime}$ denote the relaxation of the molecules. $\varepsilon^{\prime \prime}$ is a measure of energy lost, while the electric field shows the
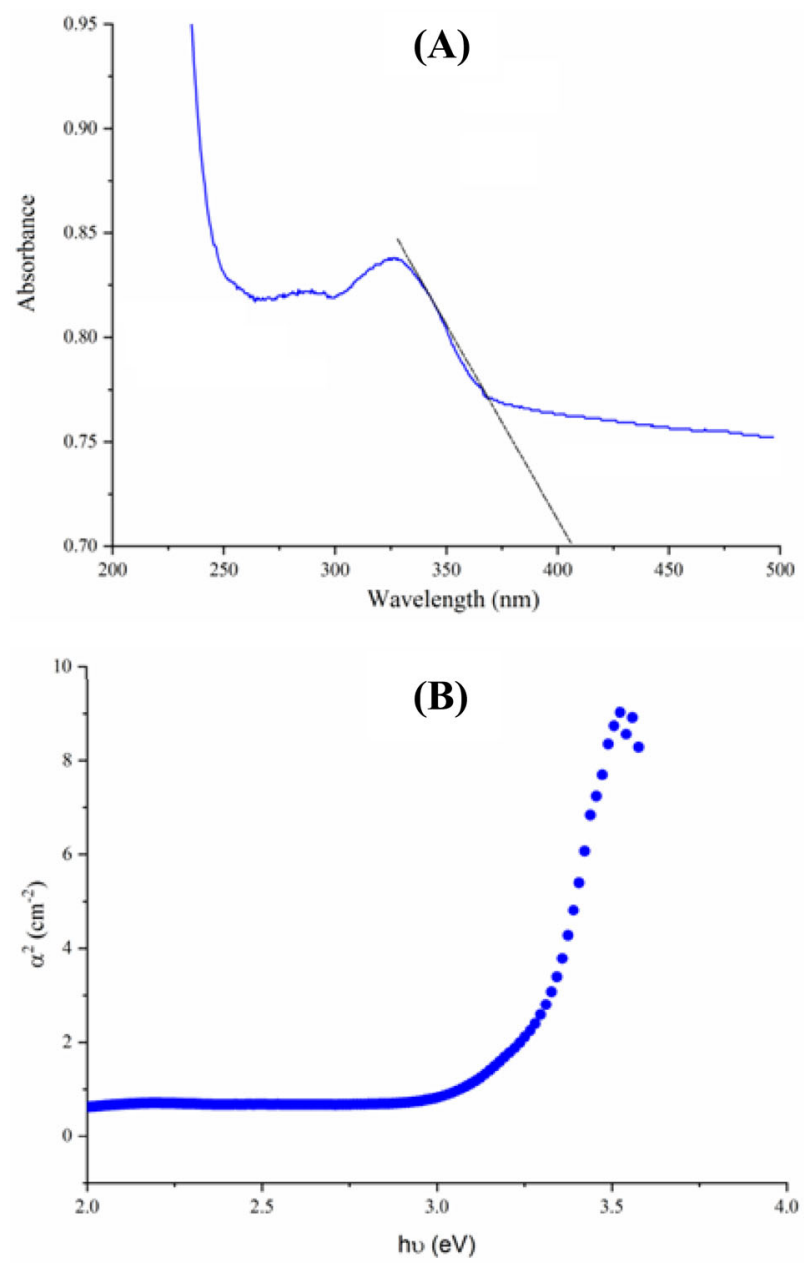

Figure 8. (A) UV-Vis spectrum and (B) plots of $\alpha^{2}$ for the poly(NIPAM-co-HEMA 0.77) film. 

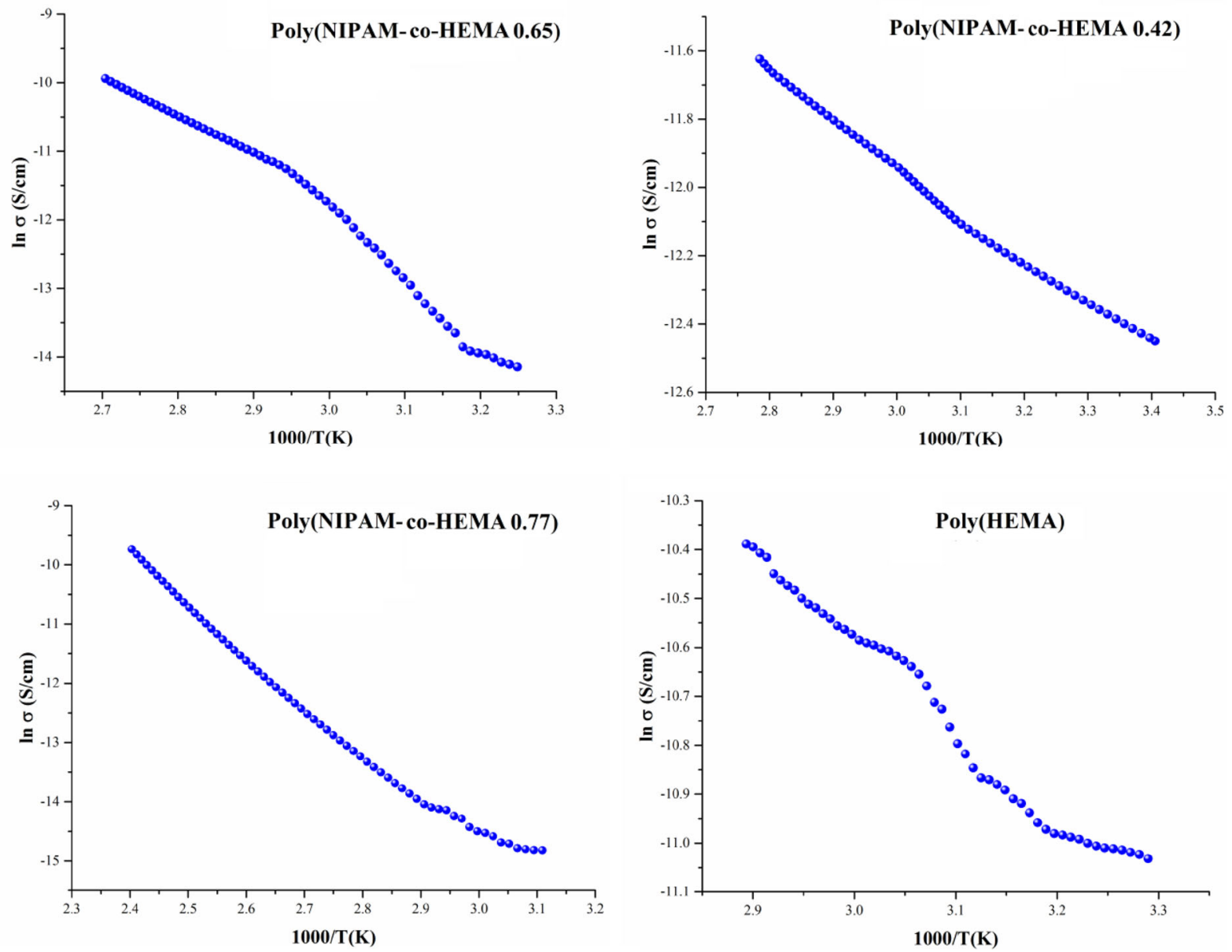

Figure 9. Temperature dependence of dc conductivity for the composite series doped with 10 wt $\%$ graphite.

energy stored in a material [35]. So, the increase in the amount of the filler will increase the composite polarity and also increase both $\varepsilon^{\prime}$ and $\varepsilon^{\prime \prime}$ [36,37]. In figure $7 \mathrm{C}$, when the added graphite percentage was about $8-10 \mathrm{wt} \%$, a very significant change occurred in the curves and the electrical conductivity of the composite increased with an increase in the filler content. When the percentage of graphite increased from 8 to $10 \mathrm{wt} \%$, the $\sigma_{\mathrm{ac}}$ increased from $7.65 \times 10^{-7}$ to $1.14 \times 10^{-6}$. The insulator polymers are transformed into the semiconductor. This transition is satisfactory and can be explained by the percolation theory and the formation of conductive networks in the composites [38]. Almost all materials can exhibit conductivity at high-frequencies. But even at low-frequencies, conductivity behaviour is only a characteristic property of conductors and semiconductors $[39,40]$. The absorption data were analysed using the well-known relationship for nearedge optical absorption of semiconductors:

$$
\alpha h v=k^{\prime}\left(h v-E_{\mathrm{g}}\right)^{n / 2},
$$

where $k^{\prime}$ is a constant and $n$ is a constant equal to 1 for direct band gap semiconductors and 4 for indirect band gap semiconductor materials [41,42]. The variation of $\alpha^{2} v s . h v$ in figure $8 \mathrm{~B}$ is linear at the absorption edge, which confirms that poly(NIPAM-co-HEMA 0.77) is a direct band gap semiconductor. Extrapolating the straight-line portion of the $\alpha^{2}$ $v s$. $h v$ plot to the zero absorption coefficient value gives the band gap energy, $E_{\mathrm{g}}$. The estimated band gap was calculated as $3.09 \mathrm{eV}$. Similar results are also reported by others $[43,44]$.

Graphs of $\ln \sigma-1000 / T$ (figure 9) are drawn to investigate the temperature dependence of the dc conductivities of composites doped with $10 \mathrm{wt} \%$ graphite at 298-423 K. The composites exhibited a linear relationship between $\ln \sigma-1000 / T$. This relationship is explained by the Arrhenius formula given below.

$$
\sigma=\sigma_{0} \exp \left(-\frac{E_{\mathrm{a}}}{k_{\mathrm{B}} T}\right)
$$

where $\sigma_{0}$ the pre-exponential factor, $E_{\mathrm{a}}$ the activation energy, $k_{\mathrm{B}}$ the Boltzmann constant and $T$ the temperature.

An increase in the ionic conductivity as a function of temperature can be attributed to the increase in the free volume in composites showing an amorphous structure [45]. The increase in temperature provides sufficient thermal energy in 
Table 4. $E_{\mathrm{a}}$ values of the composite series doped with $10 \mathrm{wt} \%$ graphite at $1 \mathrm{kHz}$.

\begin{tabular}{lccc}
\hline Sample & Slope & $k$ & $E_{\mathrm{a}}(\mathrm{eV})$ \\
\hline Poly HEMA & 8.16 & 0.086 & 0.701 \\
Poly(NIPAM-co-HEMA 0.77) & 7.60 & 0.086 & 0.653 \\
Poly(NIPAM-co-HEMA 0.65) & 1.81 & 0.086 & 0.155 \\
Poly(NIPAM-co-HEMA 0.42) & 1.35 & 0.086 & 0.116 \\
\hline
\end{tabular}

the polymer chain and the ions in the polymer molecule can easily pass from one polymer chain to another. This process continues and therefore, increases the segmental mobility in the ions and molecules, thereby increasing the conductivity $[46,47]$. The $E_{\mathrm{a}}$ values are calculated from the slope of the $\ln \sigma-1000 / T$ lines. $E_{\mathrm{a}}$ is the threshold energy of ions to hop from one site to another in the composites with an increase in the temperature [48]. The $E_{\mathrm{a}}$ of the composites is summarized in table 4. As the HEMA ratio increased in the composites, the $E_{\mathrm{a}}$ also increased. While $E_{\mathrm{a}}$ is 0.701 for poly(HEMA), it is 0.116 for poly(NIPAM-co-HEMA 0.42). In composites containing poly(NIPAM-co-HEMA 0.24) and poly(NIPAMco-HEMA 0.33), the dc conductivity values are not given because they are outside the acceptable limits.

\section{Conclusions}

Homopolymers and copolymers at different ratios of HEMA and NIPAM were synthesized by free radical polymerization. The synthesized polymers were characterized by FTIR and ${ }^{1} \mathrm{H}-\mathrm{NMR}$. Thermal behaviours were examined by TGA and DSC and compared with each other. The $\varepsilon^{\prime}, \varepsilon^{\prime \prime}$ and $\sigma_{\mathrm{ac}}$ of homopolymers and copolymers were investigated as a function of frequency. As the HEMA ratio increased in the copolymer, both dielectric properties and conductivity are increased. Also, $\varepsilon^{\prime}$ and $\varepsilon^{\prime \prime}$ decreased with the increase in the frequency and remained almost constant at higher frequencies. The synthesized homopolymers and copolymers were doped with $10 \mathrm{wt} \%$ graphite to form composites and their electrical behaviour was examined. There was a significant increase in the $\varepsilon^{\prime}, \varepsilon^{\prime \prime}$ and $\sigma_{\text {ac }}$ of polymers with doped-graphite. The highest $\varepsilon^{\prime}$ (75) was obtained at $100 \mathrm{~Hz}$ for poly(NIPAMco-HEMA 0.77 ) filled with a $10 \mathrm{wt} \%$ graphite composite. All composites can be used in charge storing devices. Polymers that are normally insulators are transformed into semiconductors when doped with graphite. It is thought that a similar increase in $\varepsilon^{\prime \prime}$ will lead to a significant increase in application areas. The highest $\varepsilon^{\prime \prime}(26,622)$ was obtained for poly(NIPAMco-HEMA 0.77) filled with a $10 \mathrm{wt} \%$ graphite composite at $100 \mathrm{~Hz}$ and this property of the composites makes it suitable for decoupling capacitor applications. It can be noted that $\sigma_{\mathrm{ac}}$ of pure copolymers $\left(1.92 \times 10^{-9} \mathrm{~S} \mathrm{~cm}^{-1}\right)$ increases to about thousand times $\left(1.18 \times 10^{-6} \mathrm{~S} \mathrm{~cm}^{-1}\right)$ by adding $10 \mathrm{wt} \%$ graphite. The electrical properties $\left(\varepsilon^{\prime}, \varepsilon^{\prime \prime}\right.$ and $\left.\sigma_{\mathrm{ac}}\right)$ of the poly(NIPAM-co-HEMA 0.42) composite with 8, 9 and $10 \mathrm{wt} \%$ graphite contents depending on the frequency were examined and it was seen that these properties were increased with an increase in the amount of graphite. Finally, the ionic conductivity (dc conductivity) of the graphite-doped composites was investigated at $1 \mathrm{kHz}$. dc conductivities and the activation energies were calculated by using the Arrhenius equation. Composites filled with $10 \mathrm{wt} \%$ of graphite demonstrated higher dc conductivity from room temperature and was found to be $1.56 \mathrm{~S} \mathrm{~cm}^{-1}$ with a minimum activation energy (0.116) for poly(NIPAM-co-HEMA 0.42).

\section{References}

[1] Li Y C, Tjong S C and Li R K Y 2014 Synth. Met. 1601912

[2] Kuan H C, Ma C C M, Chen K H and Chen S M 2004 Power Sources 1347

[3] Sumita M, Sakata K, Asai S, Miyasaka K and Nakagawa H 1991 Polym. Bull. 25265

[4] Ma P C, Siddiqui N A, Marom G and Kim J K 2010 Compos. A: Appl. Sci. Manuf. 411345

[5] Kuilla T, Bhadra S, Yao D, Kim N H, Bose S and Lee J H 2010 Prog. Polym. Sci. 301350

[6] Sengupta R, Bhattacharya M, Bandyopadhyay S and Bhowmick A K 2011 Prog. Polym. Sci. 36638

[7] Panwar V, Park J O, Park S H, Kumar S and Mehra R M 2010 J. Appl. Polym. Sci. 1151306

[8] Calame J P 2006 J. Appl. Phys. 99084101

[9] Xu K, Erricolo D, Dutta M and Stroscio M A 2012 Superlattices Microstruct. $\mathbf{5 1} 606$

[10] Kim H S, Na J H, Jung Y C and Kim S Y 2016 J. Non-Cryst. Solids 45075

[11] Ahlatcioglu Ozerol E, Senkal B F and Okutan M 2015 Microelectron. Eng. 14676

[12] Shioyama H, Tatsumi K and Iwashita N 1998 Synth. Met. 96 229

[13] Azeem S and Zain-ul-Abdein M 2012 Int. J. Eng. Sci. 5230

[14] Panwar V and Mehra R M 2008 Eur. Polym. J. 442367

[15] Chen G H, Wu D J, Weng W G, He B and Yan W L 2001 Polym. Int. $\mathbf{5 0} 980$

[16] Zheng W, Lu X and Wong S C 2004 J. Appl. Polym. Sci. 91 2781

[17] Chen G H, Weng W G, Wu D J and Wu C L 2003 Eur. Polym. J. 392329

[18] Greenhoe B M, Hassan M K, Wiggins J S and Mauritz K A 2016 J. Polym. Sci. P. Phys. 541918

[19] Wei T, Jin C Q, Zhong W and Liu J M 2007 Appl. Phys. Lett. 91 222907

[20] He B F, Lau S and Chan H L and Fan 2009 J. Adv. Mater. 21 710

[21] Panda M, Srinivas P V and Thakur A K 2008 Appl. Phys. Lett. 92132905

[22] Biryan F and Demirelli K 2017 Fiber. Polym. 181629

[23] Tantis I and Psarras G C and Tasis 2012 Express Polym. Lett. 6 283

[24] Mohomed K, Moussy F and Harmon J P 2006 Polymer 47 3856 
[25] Pradhan D K, Choudhary R N P and Samantaray B K 2008 Int. J. Electrochem. Sci. 3597

[26] Panda R K, Muduli R, Kar S K and Behera D 2014 J. Alloys Compd. 615899

[27] Sivakumar N, Narayanasamy A, Jeyadevan B, Justin Joseyphus R and Venkateswaran C 2008 J. Phys. D: Appl. Phys. 41 245001

[28] Srivastava N K and Mehra R M 2008 J. Appl. Polym. Sci. 109 3991

[29] Lai M, Yu S and Sun R 2014 Mater. Lett. 12245

[30] Goyal R K, Jagadale P A and Mulik U P 2009 J. Appl. Polym. Sci. 1112071

[31] Shubha A, Manohara S R and Gerward L 2017 J. Mol. Liq. 247 328

[32] Samanta S, Jana K, Gupta K, Nayak A and Ghosh U C 2016 Mater. Chem. Phys. 182173

[33] Kar E, Bose N, Dutta B, Mukherjee N and Mukherjee S 2017 Eur. Polym. J. 90442

[34] Paszkiewicz S, Szymczyk A, Pilawka R, Przybyszewski B, Czulak A and RosŁaniec Z 2017 Adv. Polym. Technol. 36 21611

[35] Twombly B and Shepard D D 1994 Instrum. Sci. Technol. 22 259
[36] George S, Varghese K T and Thomas S 1999 J. Appl. Polym. Sci. 73255

[37] Nair A B, Kurian P and Joseph R 2013 Eur. Polym. J. 49247

[38] Zheng W and Wong S C 2003 Compos. Sci. Technol. 63225

[39] Linares A, Canalda J C, Cagiao M E, García-Gutierrez M C, Nogales A, Martín-Gullon I et al 2008 Macromolecules 41 7090

[40] Milani A M, Gonzalez D, Quijada R, Benavente R, ArranzAndres J and Galland G B 2015 Polymer 65134

[41] Sartale S D, Sankapal B R, Steiner M L and Ennaui A 2005 Thin Solid Films $\mathbf{4 8 0} 168$

[42] Lokhande C D, Lee E H, Jung K D and Joo Q S 2005 Mater. Chem. Phys. 91200

[43] Goudarzi A, Motedayen Aval G, Sahraei R and Ahmadpoor H 2008 Thin Solid Films $\mathbf{5 1 6} 4953$

[44] Goudarzi A, Dorbeygi N A and Ha C S 2014 RSC Adv. 459764

[45] Miyamoto T and Shibayama K 1973 J. Appl. Phys. 445372

[46] Famiza L, Madzlan A, Nasir K, Ali A M M and Muhd Z Y 2006 J. Power Sources 1591401

[47] Jeon J D, Kwak S Y and Cho B W 2005 Electrochem. Soc. 152 A1583

[48] Koduru H K, Marino L, Scarpelli F, Petrov A G, Marinov Y G, Hadjichristov G B et al 2017 Curr. Appl. Phys. 171518 